\title{
Estenosis aórtica por válvula bicúspide: una causa de muerte súbita en jóvenes deportistas
}

\section{Aortic stenosis due to bicuspid valve: cause of sudden death in young athletes}

\begin{abstract}
Resumen
La estenosis aórtica es una causa de muerte súbita frecuente durante la práctica de deporte. La anomalía congénita más habitual de la válvula aórtica es la válvula bicúspide. Se describe el caso de un varón de 19 años de edad, diagnosticado de valvulopatía y asintomático, que falleció súbitamente mientras practicaba deporte. En la autopsia es necesario, antes de abrir el anillo valvular, explorar el estado de las valvas y valorar el área de la superficie permeable.

Palabras clave: Estenosis aortica. Válvula bicúspide. Muerte súbita.

Abstract

The aortic estenosis is a reason of sudden frequent death during the practice of sport. The most frequent congenital anomaly of the aortic valve is the bicuspid valve. There is described the case of a 19-year-old male diagnositicado of valvulopatia and asymptomatic that expired suddenly while was practising sport. In the autopsy it is necessary, before the opening of the valvular ring, the examination of the condition of the valves and to value the area of the permeable surface.
\end{abstract}

Key words: Aortic stenosis. Bicuspid valve. Sudden death.

\section{Introducción}

La estenosis aórtica representa el $25 \%$ de las valvulopatías y es más frecuente en los varones que en las mujeres. Puede ser congénita (válvula bicúspide) o adquirida (reumática o degenerativa con calcificación de las valvas sigmoides) ${ }^{1}$ (Tabla 1 ). Antes del uso de los antibióticos en el tratamiento de la enfermedad reumática, esta era la principal causa de la estenosis aórtica. Actualmente, la anomalía congénita más frecuente es la válvula aórtica bicúspide, que puede ser estenótica ya en el momento del nacimiento o estrecharse con los años (generalmente en las tres primeras décadas) como consecuencia de su calcificación. La endocarditis reumática de las valvas aórticas produce una fusión de las comisuras, lo que a veces le confiere un aspecto bicuspídeo. Este trastorno hace a las valvas más vulnerables a los traumatismos y, por último, origina fibrosis, calcificación y estrechamiento adicional. La estenosis aórtica de origen reumático generalmente se asocia a afección de la válvula mitral. La mayoría de las estenosis aórticas degenerativas se observan en pacientes mayores de 65 años. En este caso, la válvula es tricúspide y destacan los depósitos cálcicos².

\section{Presentación del caso}

Varón de 19 años de edad que fallece de forma súbita mientras realizaba ejercicios de musculación en un gimnasio. La muerte fue presenciada por varios testigos que vieron cómo quedaba inconsciente y se desvanecía. Se realizaron maniobras de reanimación cardiopulmonar básica y avanzada durante 55 minutos.

Como antecedentes médicos constaban valvulopatía, sin especificar tipo ni grado de afectación, y varios

\section{F. Martín Cazorla ${ }^{1}$}

A.M. López Calvo ${ }^{1}$

L. Rubio Lamia ${ }^{2}$

${ }^{1}$ Médico Forense, Servicio de Patología Forense del Instituto de Medicina Legal de Málaga

${ }^{2}$ Profesora Doctora Ayudante,

Área de Medicina Legal y Forense, Universidad de Málaga.

Correspondencia: Fernando Martín Cazorla Servicio de Patología Forense Instituto de Medicina Legal de Málaga

Ciudad de la Justicia.

Fiscal Luis Portero García 29010 Málaga

E-mail: fernando.martin.ius@ juntadeandalucia.es

Fecha de recepción: 28. AGO. 2014

Fecha de aceptación: 28. NOV. 2014 
Tabla 1.

Causas de estenosis aórtica y su frecuencia.

Figura 1.

Válvula aórtica vista tras la sección de la aorta ascendente. Área de superficie permeable disminuida.

Figura 2. Válvula aórtica bicúspide con rafe medio en una de

las valvas.

\section{Poco frecuentes}

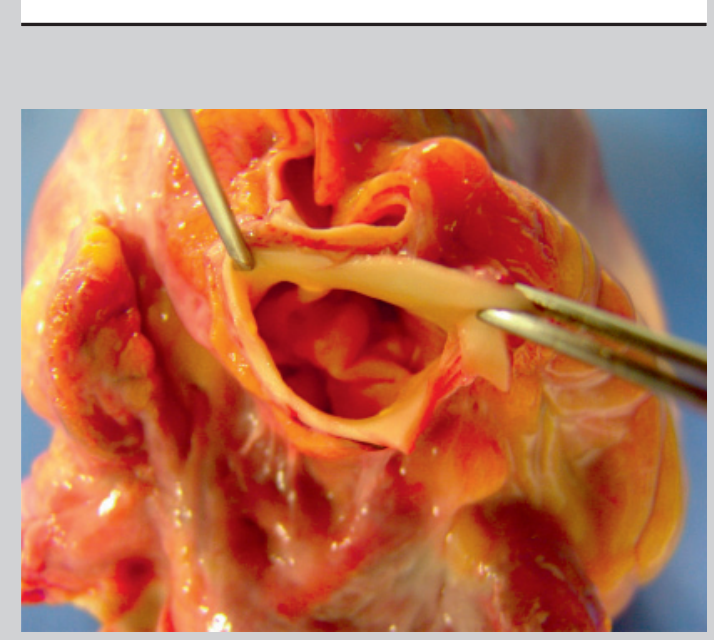

\section{Frecuentes}

Calcificación degenerativa de válvula aórtica tricúspide

Calcificación de la válvula aórtica bicúspide

Endocarditis reumática

Estenosis valvular aórtica congénita

\section{Muy poco frecuentes}

Hipercolesterolemia familiar

Enfermedad de Fabry

Lupus eritematoso sistémico

Mucopolisacaridosis

Radiación

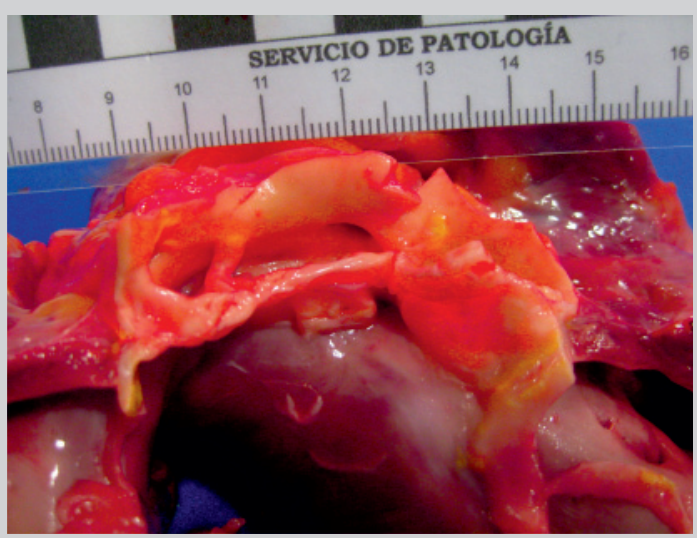

familiares fallecidos por patología cardíaca. La familia se mostró poco colaboradora a la hora de facilitar información.

En el examen externo realizado durante la autopsia se aprecian signos de reanimacion cardiopulmonar. Normoconstituido, peso 84 kg, talla 176,5 cm, índice de masa corporal 27,12. En el examen interno destaca cardiomegalia (peso del corazón de 555 g), hipertrofia concéntrica del ventrículo izquierdo (pared libre del ventrículo izquierdo y tabique interventricular de 2,1 cm cada una) y edema pulmonar (pulmón derecho 665 g y pulmón izquierdo 550 g). En el estudio macroscópico cardíaco destaca un engrosamiento de las valvas de la válvula aórtica, que disminuye de manera importante el área permeable, que medida con el cono mensurador era de $0,5 \mathrm{~cm}^{2}$ (Figura 1 ). Tras la abertura del anillo valvular, el perímetro mide $7 \mathrm{~cm}$, y se visualiza una válvula aórtica bicúspide con un rafe medio en una de las valvas junto al ostium izquierdo (Figura 2). Se establece como causa de la muerte una estenosis aórtica.

\section{Discusión}

La válvula bicúspide es la anomalía congénita de la válvula aórtica más frecuente (1-2\% de la población general y afecta 3-4 veces más a los hombres). Puede observarse sola o asociada con otras alteraciones congénitas cardíacas, como por ejemplo la coartación de aorta (el 40-50\% de los pacientes con coartación tienen la válvula aórtica bicúspide). La válvula puede presentar dos valvas de igual tamaño, pero lo más frecuente (en más del $80 \%$ de los casos) es que una de las valvas sea mayor y presente un puente o rafe medio que es el sitio de la fusión congénita de las comisuras originales. Esta alteración representa un desarrollo incompleto de una comisura o la fusión de dos valvas durante el desarrollo fetal. El rafe puede variar en tamaño, longitud y grado de diferenciación ${ }^{3}$.

Los pacientes con válvula aórtica bicúspide son generalmente asintomáticos en las primeras décadas de la vida, aunque la valvulopatía puede ser diagnosticada por auscultación o ecocardiograma. Con el paso del tiempo, la válvula tiende a calcificarse y aumenta progresivamente el grado de estenosis ${ }^{4}$. La proporción exacta de pacientes con válvula bicúspide que desarrollan estenosis es desconocida.

En el adulto, la estenosis aórtica no suele revestir importancia clínica ni hemodinámica, excepto cuando el orificio valvular se estrecha a casi $1 \mathrm{~cm}^{2}$ (o menos de $0,6 \mathrm{~cm}^{2} / \mathrm{m}^{2}$ ), es decir, cuando representa una 
reducción igual o superior a la tercera parte del área orificial normal y determina, en presencia de un gasto cardíaco basal conservado, un gradiente superior a $50 \mathrm{mmHg}$. El área crítica del orificio por debajo de la cual ocurren trastornos dinámicos importantes es de $0,5 \mathrm{~cm}^{2}$ en casos de estenosis aórtica pura y de $1,5 \mathrm{~cm}^{2}$ en casos de estenosis aórtica e insuficiencia. Cuando las valvas se fusionan completamente y se ponen rígidas, en especial si hay cierta retracción y acercamiento de las cúspides, el orifico aórtico queda abierto durante la diástole y la sístole y aparece una verdadera insuficiencia cardíaca ${ }^{5}$.

La hipertrofia cardíaca generada en el curso de los años por la sobrecarga de presión es el mecanismo de compensación que mantiene el gasto cardíaco y permite mantener al paciente asintomático hasta la sexta década de la vida. Sin embargo, los adultos con válvula bicúspide desarrollan disfunción valvular significativa y síntomas 10-20 años antes. Los tres síntomas cardinales son disnea de esfuerzo, angina de pecho y síncope ${ }^{5}$.

En nuestro caso, el paciente falleció de forma súbita mientras realizaba ejercicio. Diversos autores cifran en un $10-20 \%$ los pacientes con estenosis aórtica que fallecen de forma súbita, tal vez como consecuencia de una probable arritmia. La muerte súbita como primera manifestación es muy infrecuente $(<1 \%$ por año) en los adultos ${ }^{6}$. Durante el estudio macroscópico del corazón pudimos observar una hipertrofia concéntrica del ventrículo izquierdo, lo que indica la existencia de un mecanismo compensatorio de la estenosis aórtica (Figura 3). La válvula era bicúspide con rafe medio, y a cada lado se disponían los ostia coronarios. Las valvas apenas tenían nódulos calcificados, ni tampoco el rafe. Se utilizó un cono mensurador para calcular el área de superficie permeable de la válvula, que era menor de $1 \mathrm{~cm}^{2}$, por lo que se considera como una estenosis aórtica grave. A falta de cono mensurador, a efectos orientativos puede introducirse la punta del quinto dedo, que si

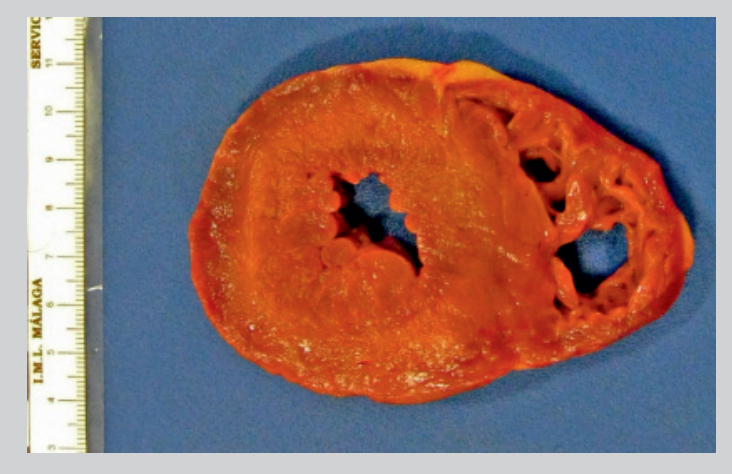

Figura 3.

Hipertrofia concéntrica del ventrículo izquierdo. no atraviesa la válvula explorada nos indica que el área del orificio es inferior a $1 \mathrm{~cm}^{2}$.

Como ya se ha expuesto, la muerte se produjo mientras estaba realizando un ejercicio intenso, lo que supuso un aumento de las necesidades de oxígeno en un corazón ya con una demanda mayor de este por la hipertrofia ventricular izquierda, que no pudo compensarse con un mayor aumento del gasto cardíaco debido a la estenosis aórtica.

\section{Conclusiones}

Lo llamativo del caso que se expone es la muerte súbita en un adulto joven mientras realizaba deporte por una estenosis aórtica congénita, cuando lo frecuente es que la muerte por esta causa ocurra entre la sexta y la octava décadas por calcificación degenerativa de la válvula.

El hallazgo durante la autopsia de una válvula aórtica bicúspide no debe ser interpretado como un hallazgo menor, puesto que puede asociarse con otras patologías como la disección aórtica.

El área del orificio valvular debe medirse con un cono mensurador para un correcto diagnóstico.

\section{Bibliografía}

1. Betriu Gibert A, Roig Minguell E. Valvulopatías. En: Farreras-Rozman, Medicina interna. $15^{\mathrm{a}}$ ed. Madrid: Elsevier; 2004

2. Fineschi V, Baroldi G, Silver M. Pathology of the heart and sudden death in forensic medicine. USA Taylor \& Francis; 2006.

3. Sheppard M. Practical cardiovascular pathology. 2nd ed. London: Hodder Arnold; 2011.

4. Fernández F, Mayorga M. Estenosis aórtica. REA. 2012;10:7.

5. O'Gara P, Loscalzo J. Cardiopatías valvulares. En: Harrison, Principios de medicina interna. $18^{\mathrm{a}} \mathrm{ed}$. McGraw-Hill Interamericana ; 2012.

6. Ruiz Ruiz FJ, González Cortijo J, León Cinto C, Sánchez Miret JI. Estenosis aórtica asintomática y muerte súbita. An Med Intern. 2003;20:529-31. 